\title{
Conventional and emerging roles of the energy sensor Snf1/AMPK in Saccharomyces cerevisiae
}

\author{
Paola Coccetti ${ }^{1,2, *}$, Raffaele Nicastro ${ }^{1,3}$ and Farida Tripodi ${ }^{1,2}$ \\ ${ }^{1}$ Department of Biotechnology and Biosciences, University of Milano-Bicocca, Milan, Italy. \\ 2 SYSBIO, Centre of Systems Biology, Milan, Italy. \\ ${ }^{3}$ Present address: Department of Biology, University of Fribourg, Fribourg, Switzerland. \\ * Corresponding Author: \\ Paola Coccetti, Department of Biotechnology and Biosciences, University of Milano-Bicocca, Milan, Italy; \\ E-mail: paola.coccetti@unimib.it
}

\begin{abstract}
All proliferating cells need to match metabolism, growth and cell cycle progression with nutrient availability to guarantee cell viability in spite of a changing environment. In yeast, a signaling pathway centered on the effector kinase Snf1 is required to adapt to nutrient limitation and to utilize alternative carbon sources, such as sucrose and ethanol. Snf1 shares evolutionary conserved functions with the AMP-activated Kinase (AMPK) in higher eukaryotes which, activated by energy depletion, stimulates catabolic processes and, at the same time, inhibits anabolism. Although the yeast Snf1 is best known for its role in responding to a number of stress factors, in addition to glucose limitation, new unconventional roles of Snf1 have recently emerged, even in glucose repressing and unstressed conditions. Here, we review and integrate available data on conventional and non-conventional functions of Snf1 to better understand the complexity of cellular physiology which controls energy homeostasis.
\end{abstract}

doi: 10.15698/mic2018.11.655

Received originally: 29.06.2018;

in revised form: 23.08.2018,

Accepted 23.08.2018,

Published 29.09.2018.

Keywords: budding yeast, metabolism, stress response, aging, transcription, signaling, cell cycle, endocytosis, DNA damage, glucose repression.

\section{Abbreviations:}

AIS - autoinhibitory sequence.

\section{INTRODUCTION}

Cell growth and proliferation require a high amount of energy for biosynthetic pathways. Cells take energy from nutrient intake and both unicellular and multicellular eukaryotes have evolved systems that allow dynamic sensing of energy sources, mainly sugars. The class of Snf1/AMPK (Sucrose non-fermenting/AMP-activated protein kinase) plays a key role as a guardian of cellular energy [1]. They are highly conserved serine/threonine kinases and their primary role is the integration of signals regarding nutrient availability and environmental stress, ensuring the adaptation to those conditions and cell survival [2].

Here we discuss the mechanisms of action of Snf1, a member of the Snf1/AMPK family in Saccharomyces cerevisiae and its conventional roles in the regulation of metabolism, stress response and aging. In addition, we also focus on recent advances showing emerging functions of Snf1 on the modulation of key processes such as endocytosis and cellular trafficking as well as cell cycle, proliferation and metabolism.

\section{SNF1 COMPLEX COMPOSITION}

Protein kinase Snf1 in yeast is a heterotrimeric complex made by the catalytic $\alpha$ subunit Snf1, a regulatory $\beta$ subunit (alternatively Gal83, Sip1 and Sip2) and the $\gamma$ subunit Snf4 [3].

The catalytic $\alpha$ subunit (encoded by the SNF1 gene) was identified in a screening of mutants unable to grow in presence of sucrose as carbon source [4]. The Snf1 subunit is constitutively expressed and constituted by a catalytic $\mathrm{N}$ terminal domain and a $\mathrm{C}$-terminal regulatory region. The regulatory region presents a short autoinhibitory sequence (AIS) (380 - 415 aa) and a domain which mediates the interactions with the $\beta$ subunits of the complex. The autoinhibitory domain interacts with both the regulatory subunit Snf4 and the kinase domain of Snf1. The interaction with Snf4 relieves the inhibition of the AIS allowing the phosphorylation of Thr210 residue of Snf1 that determines its activation $[5,6]$.

In S. cerevisiae, three $\beta$ subunits (Gal83, Sip1 and Sip2) are present. They share partially redundant functions, since only the triple mutant $\operatorname{sip} 1 \Delta \operatorname{sip} 2 \Delta$ gal $83 \Delta$ strain shows 


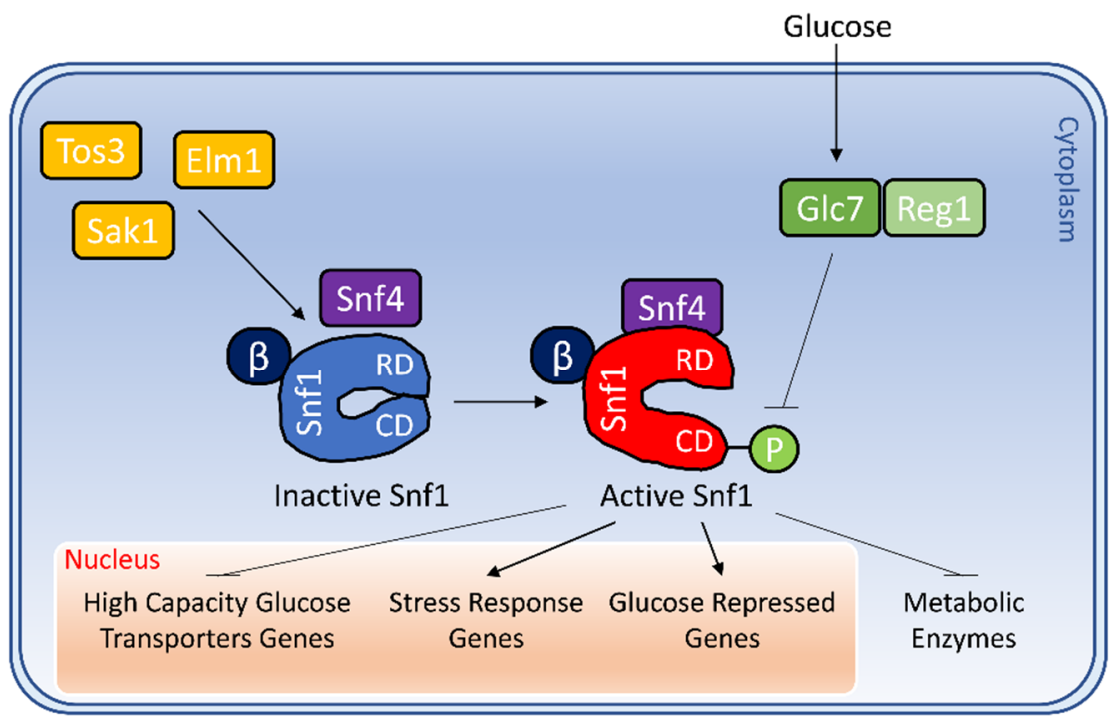

FIGURE 1: Schematization of the activation of Snf1 and its main conventional functions. Snf1 complex is composed by the $\alpha$ subunit Snf1, the $y$ subunit Snf4 and one of three alternative $\beta$ subunits Gal83, Sip1 or Sip2. Snf1 is phosphorylated on T210 by the upstream kinases Sak1, Tos3 and Elm1, while it is de-phosphorylated by the phosphatase complex Glc7/Reg1. When active, Snf1 phosphorylates transcription factors which regulate the expression of genes involved in glucose transport, stress response and glucose repression. In addition, Snf1 directly phosphorylates some metabolic enzymes. See text for details.

growth defects when glycerol or ethanol are added as carbon sources $[7,8]$. The $\beta$ subunits contain a conserved $C$ terminal sequence in which two domains are present: the KIS domain (Kinase Interacting Sequence) that mediates the interaction with the $\alpha$-subunit Snf1 [9] and the ASC domain (Association with SNF1 kinase Complex) that allows the interaction with Snf4 [10]. Differently, the N-terminal sequence is specific for each $\beta$ subunit and confers a different subcellular localization pattern to each protein. All three proteins are mainly cytoplasmic in presence of high glucose concentrations. Upon glucose depletion, Sip1 relocalizes to the vacuolar membrane, Gal83 relocalizes to the nucleus, while Sip2 remains cytoplasmic [11]. Thus, the role of the $\beta$ subunits is to interact with Snf1 and to modulate its subcellular localization $[11,12]$. The particular localization of the kinase complexes with different $\beta$ subunits confers specialized functions. For example, Sip1 alone is not able to sustain growth on ethanol or glycerol and determines a very low kinase activity of the complex [13], Sip2 function seems to be involved in the mechanism of cellular aging [14], while Gal83 plays its main role in the Snf1-dependent transcriptional regulation, since in low glucose it determines the nuclear localization of the Snf1 complex thank to its NLS (Nuclear Localization Signal). On the contrary, NES (Nuclear Export Signal), present on the sequence of Gal83, allows the exit from the nucleus of the complex when high glucose concentrations are available [15]. In addition, Gal83 mediates the interaction of Snf1 with some substrates, such as the transcription activator Sip4 [16] and the transcriptional apparatus [17]. It has also been shown that deletion of the glycogen binding domain (GBD) of Gal83 leads to a constitutive activation of Snf1, which results able to modulate the expression of some Snf1-regulated genes also in high glucose concentrations [18]. The GBD domain of Gal83 also interacts with the Reg1/Glc7 phosphatase complex, responsible for Snf1 inactivation [18]. Taken together those data suggest that Gal83 plays a dual role regulating nuclear localization of Snf1 in low glucose and guaranteeing its inactivation in high glucose.

Similarly to SNF1, the gene encoding the $\gamma$ subunit, SNF4, was identified by isolation of a sucrose non fermenting mutant [4]. Snf4 is a constitutively expressed protein that binds both the $\alpha$ and $\beta$ subunits of the Snf1 complex $[10,19]$. The role of Snf4 is to relieve the inhibition of Snf1 interacting with its AIS domain, stabilizing the Snf1 complex in the active conformation [20]. In fact, SNF4 deletion causes a decreased kinase activity of Snf1, whereas deletion of the AIS domain of Snf1 fully complement the phenotype of a snf $4 \Delta$ strain $[19,20]$. Remarkably, the activating phosphorylation of Thr210 residue of Snf1 is still detectable in a snf $4 \Delta$ strain [21] and in high glucose Snf4 seems to be required for the proper inactivation of Snf1 mediated by the phosphatase complex Reg1/Glc7 [18]. Thus, these findings indicate that Snf4 plays a complex role in the regulation of Snf1.

\section{REGULATION OF SNF1 ACTIVITY}

Snf1 complex is activated through phosphorylation of the Thr210 of the $\alpha$ subunit by one of the three constitutively active upstream kinases Sak1, Tos3 and Elm1 [22, 23] (Fig. 1). This phosphorylation is essential for Snf1 activity, since the sak1 1 tos $3 \Delta$ elm $1 \Delta$ strain shows the same phenotype of a snf $1 \Delta$ strain, such as growth defects in presence of limiting glucose or alternative carbon sources like glycerol or ethanol [22].

Although Snf1 phosphorylation is a key step for its activation, a non-phosphorylatable Snf1 mutant (Snf1-T210A) retains a low catalytic activity, originating intermediate phenotypes [24, 25]. Also, the mutation of the lysine which constitutes the ATP binding site in the kinase domain (Snf1K84R), which for many aspects mimics the loss of Snf1 protein, still confers a slight catalytic activity [26-29].

On the other side, in response to high glucose concentrations Snf1 is inactivated through dephosphorylation of Thr210 by the Gcl7 protein phosphatase (also known as 
PP1), which is targeted to Snf1 by the adaptor subunit Reg1 $[30,31]$. Reg1 interacts both with Glc7 and Snf1 when glucose is largely available in the culture medium and loss of Reg1 leads to the constitutive activation of Snf1 [32-34]. It has been reported that in high glucose concentration, Hxk2 (Hexokinase 2) regulates the activity of PP1 and consequently the activation of Snf1 kinase [31].

Active Snf1 phosphorylates serine and threonine residues contained in the consensus pattern $\Phi-x-R-x-x-S / T-x-x-x-\Phi$, where $\Phi$ is a hydrophobic residue [35].

Differently from its mammalian homolog AMPK, yeast protein kinase Snf1 is not allosterically activated by AMP [36]. However, it was demonstrated that ADP molecules are able to bind the $\gamma$ subunit Snf4, preventing Snf1 dephosphorylation mediated by Glc7 [37, 38].

The structure of the kinase domain of Snf1 showed that it is a dimer, which represents an inactive form of the kinase, since Thr210 is inaccessible for phosphorylation by the activating kinases [39]. Although these results suggest the existence of another layer of regulation of Snf1 activity, further investigation is required to better elucidate its physiological relevance.

Interestingly, some recent evidence indicates additional mechanisms that regulate Snf1 activity: (i) phosphorylation of Ser214, inside the activation loop, downregulates Snf1 function [40]; (ii) SUMOylation of the catalytic $\alpha$ subunit Snf1 inhibits its activity, possibly by attenuating its levels in the cell and/or favoring the inactive conformation of the kinase [41]; (iii) the SAGA acetyl transferase complex deubiquitylates Snf1 affecting the stability of the complex and its kinase activity [42]; (iv) the ubiquitin-associated motif (UBA) of the a subunit Snf1 indirectly regulates SNF1 gene expression and Snf1 interaction with the $\gamma$ subunit Snf4 [43].

\section{NETWORK OF SNF1 PHYSICAL INTERACTORS}

A total of 216 proteins physically interacting with Snf1 are annotated in SGD (Saccharomyces Genome Database, http://www.yeastgenome.org), 92 of which are also Snf1 substrates (identified by high throughput or low throughput assays). In Figure 2 we clustered them on the base of their function. Apart from the most known interactors involved in Snf1 complex regulation, transcription, histone modification, signaling and metabolism, there are many proteins which regulate translation, ribosome function, intracellular transport/trafficking and cell cycle. In addition, some of them are also proteins of the ubiquitin/proteasome machinery, chaperones and Fe/S cluster proteins (Fig. 2). Remarkably, only a few of them have been extensively investigated for the physiological relevance of Snf1-dependent phosphorylations, suggesting that many functions of Snf1 are still to be discovered.

\section{CONVENTIONAL ROLES OF SNF1}

\section{Snf1 and the regulation of transcription}

The most studied function of Snf1 is the regulation of transcription, involving more than 400 genes [46]. Snf1 acts both on transcription factors and on chromatin remodeling [4750], as also highlighted by the number of its interactors belonging to these two classes of proteins (Fig. 2).

Mig1 is the most important glucose-regulated transcriptional repressor [51]. Mig1 is phosphorylated by Snf1 on four sites when glucose is scarce, causing the activation of a NES (Nuclear Export Signal) sequence that causes its translocation from the nucleus to the cytoplasm through the exportin Msn5 [48, 52, 53]. Important in the regulation of Mig1 is hexokinase $\mathrm{Hxk} 2$, which interacts with the transcriptional repressor directly in the nucleus to avoid its phosphorylation by Snf1, thus providing a link between glucose metabolism and transcription of glucose-repressed genes [54]. Mig1 represses about 90 genes, including those coding for enzymes required for the metabolism of sucrose (SUC2), maltose (the MAL regulon) and galactose (GAL4) [55]. Furthermore, Mig1 controls the expression of high-affinity glucose transporters, required when glucose is scarce (HXT2, HXT4) [56], represses TPS1, essential for the metabolism of trehalose [57] and genes coding for enzymes of the TCA cycle [58].

Besides Mig1, Snf1 regulates the activity of other transcription factors. Cat8 and Sip4, which bind Carbon Source Responsive Elements (CSRE), regulate the expression of gluconeogenic genes [59] and are activated by Snf1 phosphorylation $[49,60]$. Cat8 activates the expression of glucose-repressed genes alongside transcription factor Adr1, which is itself a target of Snf1 [61, 62]. Moreover, in a fine mechanism of positive feedback, the CAT8 gene is activated by Snf1 through inhibition of Mig1 [47]. In addition, Gcn4, the transcription factor responsible for the expression of genes involved in amino acid biosynthesis, is also regulated by Snf1 when in complex with the $\beta$ subunit Gal83 or Sip1, but not Sip2 [63].

Snf1 has been reported to phosphorylate Ser10 of histone $\mathrm{H} 3$ and to promote the acetylation on Lys14 of histone $\mathrm{H} 3$ by Gcn5, a component of the SAGA complex [50]. Snf1mediated regulation of histone $\mathrm{H} 3$ is involved in the expression of $A D Y 2$ gene. In fact, Snf1 stimulates the binding of Gcn5 and the acetylation of histone $\mathrm{H} 3$ at $A D Y 2$ promoter, promoting the transcription of this gene [64].

\section{Snf1 and the regulation of metabolism}

Besides its role in regulating the transcription of several genes involved in metabolism, Snf1 directly regulates, through phosphorylation, important metabolic enzymes. In fact, together with the class of transcription factors and regulators, proteins linked to metabolism are the most abundant among Snf1 interactors (Fig. 2). Probably the most impactful function exerted by Snf1 as a direct regulator of metabolism is the regulation of the acetyl-CoA carboxylase Acc1 [65]. In yeast, loss of Snf1 causes a dramatic accumulation of fatty acids and the carbon overflow into the fatty acid biosynthetic pathway has been shown to cause inositol auxotrophy mediated by the impairment of INO1 expression [65, 66]. Moreover, the excessive alloca- 


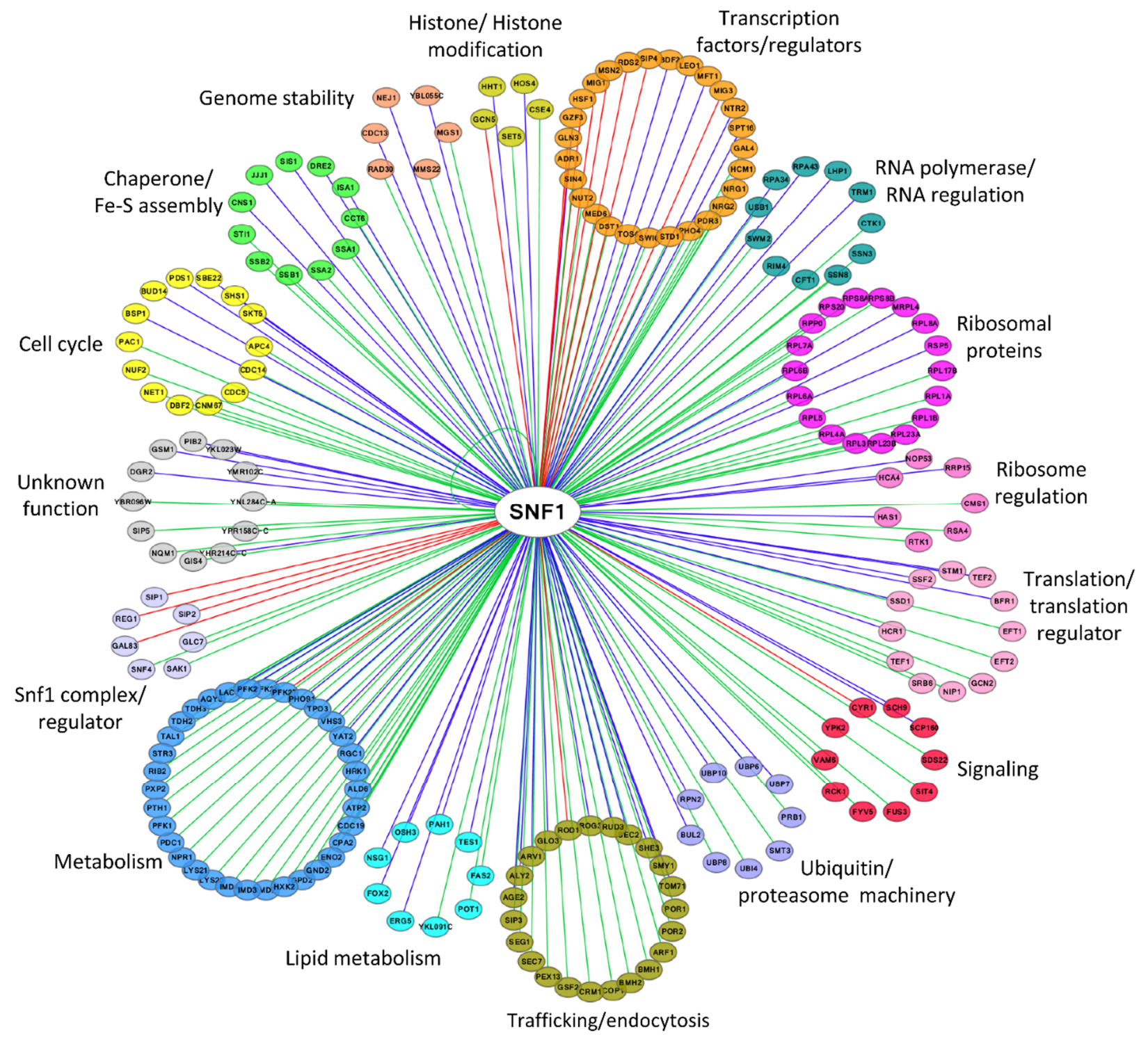

FIGURE 2: Network of Snf1 physical interactors. The network reports the known physical associations obtained from SGD (Saccharomyces Genome Database, http://www.yeastgenome.org). Interactors are clustered according to their function and colored differently. When the interactor is also a substrate of Snf1 according to the Yeast Kinase Interaction Database (KID, http://www.moseslab.csb.utoronto.ca/KID/; [44]), the edge is colored in red if phosphorylation was analyzed by low throughput assays (LTP in vitro kinase assays; in vitro phosphorylation site mapping; in vivo phosphorylation site mapping; phosphorylation reduced or absent in kinase mutant) or in blue if phosphorylation was assayed only by high throughput analysis (protein chip data for in vitro phosphorylated substrate; HTP in vitro phosphorylation). Data visualization and analysis was performed with Cytoscape [45].

tion of carbon into fatty acids causes a depletion of the intracellular acetyl-CoA pool, and thus a global reduction of acetylation of histones, of Swi4, the DNA-binding protein of the transcription factor SBF [67], and of the $\beta$-subunit Sip2 [68].

Snf1 was also shown to phosphorylate Pfk27, the second isoform of 6-phosphofructo-2-kinase [69]. Upon glucose removal, Snf1 phosphorylates Pfk27 in its N-terminal domain, leading to the SCF ${ }^{G r 1}$-dependent degradation of Pfk27 [69]. In particular, Snf1-dependent phosphorylation is required to promote Pfk27 association with the F-box protein Grr1
[69], thus leading to Pfk27 turnover and consequently to a reduction of fructose-2,6-bisphosphate. The importance of Pfk27 turnover is highlighted by the fact that expression of a non-phosphorylatable and non-degradable Pfk27 protein inhibits growth on glycerol [69].

Moreover, Snf1 phosphorylates Gpd2, the glycerol-3phosphate dehydrogenase required for anaerobic growth, thus inhibiting glycerol synthesis during the diauxic shift. In fact, it was reported that Snf1 phosphorylates Gpd2 on Ser72 priming Gpd2 for subsequent phosphorylation on Ser75, probably by Yck1 [70]. 


\section{Snf1 and PKA crosstalk}

In yeast, the main pathway activated by glucose is the PKA pathway, involved in metabolism, growth and proliferation [71-73]. Targets of PKA include glycolytic and gluconeogenetic enzymes, proteins involved in the metabolism of storage carbohydrates, transcription factors regulating stress response, ribosomal biogenesis, and carbohydrate metabolism. Active PKA directly stimulates glycolysis, cell growth and cell cycle progression, at the same time gluconeogenesis, stress resistance and mobilization of glycogen and trehalose are down-regulated [71, 74]. Several examples of cross-talk between Snf1 and PKA pathways have been reported [75]. Indeed, both kinases regulate the activity of the same transcription factors. Adr1, the transcriptional activator of glucose-repressed genes, is inactivated by PKA and activated by Snf1 which promotes its phosphorylation [76, 77]. Msn2, the stress-responsive transcriptional activator, which is a well-known target of PKA, is phosphorylated also by Snf1 in glucose starvation [78]. PKA indirectly controls the localization of the $\beta$ subunit Sip 1 and, as a consequence, of the Snf1-Sip1 complex [12]. In addition, PKA contributes to regulate Sak1, one of the Snf1-activating kinases [79].

Notably, recent data nicely complement observations of a cross-talk between Snf1 and PKA. Indeed, the adenylate cyclase Cyr1 and Snf1 interact in a nutrient-independent manner [29]. Active Snf1 phosphorylates Cyr1 and negatively regulates CAMP content and PKA-dependent transcription [29]. Moreover, loss of Snf1 causes an alteration in the phosphorylation pattern of adenylate cyclase [29], suggesting that the crosstalk between Snf1 and PKA is more complex than actually reported and needs to be further investigated.

\section{Snf1 and the regulation of TORC1}

The Target Of Rapamycin Complex I (TORC1) is a highly conserved nutrient-responsive regulator of cell growth and metabolism in all eukaryotes [80-82]. Contrary to AMPK, which is active under nutrient-poor conditions, TORC1 is active under nutrient-rich conditions in budding yeast and also in the presence of growth factors in higher eukaryotes [83, 84]. In yeast, TORC1 is composed of Tor1, Kog1/Raptor, Lst8 and Tco89 [81, 85, 86]. Kog1/Raptor is known to recruit substrates such as 4EBP1 and ribosomal S6 kinase (S6K) to the TORC1 complex $[87,88]$ and is required for the regulation of its activity $[80,89]$.

Kog1 is phosphorylated by Snf1 under glucose deprivation, as AMPK does on the ortholog Raptor [90], confirming a conserved regulatory function of Snf1/AMPK on TORC1 complex. Nevertheless, the role of Snf1-dependent phosphorylation on Kog1 is somehow different, since Snf1 phosphorylation stimulates the dissociation of the Kog1-Tor1 complex and the formation of Kog1-bodies by limiting the level of active TORC1 complex in the cell [90]. Thus, although the final result of Snf1 phosphorylation is the inactivation of TORC1 activity, this is reached by increasing the activation threshold of TORC1 to guarantee a cellular commitment to a quiescent state and then survival in starvation condition [90].
In the presence of nutrients, TORC1 phosphorylates and activates Sch9, the ortholog of S6K in yeast which, together with other substrates, drives ribosome biosynthesis [91-93]. Through an in vitro kinase assay and epistasis analysis, Sch9 has been shown to be also a target of Snf1, indeed total Sch9 phosphorylation is reduced in snf1 $\Delta$ mutant [94]. On the other hand, Snf1-hyperactive cells display a dramatic decrease of TORC1 activity [95]. Moreover, Snf1 activity is required for the downregulation of TORC1-dependent phosphorylation on Sch9 also in glucose deprivation [96].

Interestingly, Orlova and coworkers showed that rapamycin treatment results in a significant increase of Thr210 phosphorylation on Snf1 [97], suggesting a reciprocal regulation of Snf1 by TORC1 and a more complex crosstalk between the two signaling pathways.

TORC1 activity is involved in the regulation of autophagy, a cellular recycling system that degrades proteins and organelles by delivery to the vacuole in response to nutrient deprivation $[98,99]$. In yeast, nitrogen starvation, which induces TORC1 inhibition, Atg13 dephosphorylation as well as Atg1 phosphorylation, results in activation of autophagy [100]. Remarkably, although Snf1 has been proposed as a positive regulator of nitrogen-induced autophagy probably because of its phosphorylation on Atg1 [101], in snf1A cells, the translocation of GFP-Atg8 to the vacuole is reduced by $50 \%$ compared to the wild type [102]. Moreover, Snf1 activity is essential for glucose starvation-induced autophagy, and mitochondrial respiration is a required feature for this energy deprivation condition [102]. These interesting results indicate that further investigations are required to better elucidate the different mechanisms which regulate nitrogen- and glucose-induced autophagy, as well as how Snf1 is involved in such a regulation.

\section{Snf1 and the regulation of stress response}

Besides nutritional deprivation, Snf1 is also involved in the response to other cellular stresses. Snf1 activity protects against toxicity caused by cadmium [103], hygromycin B [26], hydroxyurea [24], selenite [104], and iron [105]. Snf1 also regulates HSF (Heat Shock transcription Factor) ensuring the cellular resistance to high temperature, oxidative stress $[106,107]$ and counteracts the activity of the transcriptional inhibitor Nrg1, promoting the expression of ENA1, responsible for $\mathrm{Na}^{+}$ions detoxification [108].

In addition, protein kinase Snf1 regulates the Unfolded Protein Response (UPR), the evolutionary conserved pathway activated when improperly folded proteins accumulate and induce endoplasmic reticulum (ER) stress [109, 110]. ER misfunction causes severe disease conditions [110], thus the elucidation of the molecular mechanism by which AMPK regulates UPR signaling attracts the increasing interest of cell biologists. Nevertheless, the role of Snf1 in this pathway is still not clear, since partially discrepant data were published on yeast [111, 112]. Mizumo and coworkers support a negative role of Snf1 in such a regulation, showing that the deletion of SNF1 gene and Snf1 activation cause increased and decreased resistance to ER stress, respectively [112]. On the contrary, although results from Casamayor's laboratory highlight that Snf1 activation induces 
hypersensitivity to ER-stress-inducer agents [111], they also reported that snf1 $\Delta$ cells are more sensitive to tunicamycin, a known inducer of ER stress [113].

Thus, even though these data indicate an interesting role for Snf1 in the regulation of ER stress response, more work is needed to understand the underlying molecular mechanism.

\section{Snf1 and the regulation of DNA damage}

Interesting results from Simpson-Lavy and collaborators recently show cross-talk between Snf1 and protein kinases involved in DNA damage (Mec1/ATR and Tel1/ATM) [114]. Phosphorylation of the SUMO E3 ligase Mms 21 by Mec1 and Tel1 induces SUMOylation and inactivation of Snf1, in response to DNA damage. Thus, fermentation increases while respiration is switched off. Remarkably, inactivation of Snf1 activity by SUMOylation does not affects its phosphorylation at Thr210, indicating that SUMOylation and phosphorylation of Snf1 are independently regulated. The authors suggest that this metabolic switch may protect yeast cells from oxidative stress and propose interesting parallelisms with Warburg effect in cancer cells [114].

\section{Snf1 and the regulation of aging}

Given the role of AMPK kinase in the regulation of energy homeostasis, it is not surprising the existence of a strong relationship between aging and the AMPK pathway [115-119]. Indeed, hallmarks of the aging process such as mitochondrial dysfunction [120], autophagy [121], endoplasmic reticulum stress [122] and DNA damage repair [123] are regulated by AMPK. Importantly, both pharmacological stimulation and exercise increase AMPK activity in skeletal muscle of young rats but not in old ones [124]. Moreover, AMPK-dependent acetyl-CoA carboxylase and mitochondrial biogenesis are impaired with aging [124]. These and other results suggest that the basal activity of AMPK declines with aging, contributing to the dysregulation of intracellular metabolism.

The first evidence of the involvement of Snf1/AMPK in the aging process in yeast occurred several years ago when Asharafhi and co-workers discovered that Snf1 activity increased in replicative aging even in the presence of abundant glucose in the environment [14]. Moreover, loss of the $\beta$-subunit Sip2 accelerates aging [14] and Sip2 acetylation enhances its interaction with Snf1, decreases the kinase activity of the complex and extends Replicative Life Span (RLS, an aging model of mitotically active cells) [94]. Thus, in a yeast model of replicative aging, these results indicate that Snf1 inactivation promotes longevity [94].

On the contrary, in a yeast model of Chronological Life Span (CLS, a model of aging in post-mitotic mammalian cells), Snf1 activity is critical for the extension of CLS in caloric restriction condition and cells deleted for SNF1 gene have a very short CLS $[125,126]$. Accordingly, the upregula tion of Snf1 activity extends the life span [127] and drugs like metformin (which activates AMPK) are being proposed for the treatment of age-associated disorders [128].

Taken together these data indicate that Snf1 activity promotes longevity in CLS while accelerates RLS, showing distinct and opposite mechanisms in the regulation of aging, as also reported for other proteins in yeast $[129,130]$.

\section{NON CONVENTIONAL ROLES OF SNF1 \\ Snf1 and the regulation of endocytosis}

Recent data suggest that Snf1 function is not limited to conditions of carbon limitation. One of such functions is the regulation of proteins involved in endocytosis and cellular trafficking, indeed several interactors and substrates of Snf1 are in this cluster (Fig. 2). Snf1 interacts with and phosphorylates the $\alpha$-arrestin Rod1 $[27,131,132]$, which regulates endocytosis of the lactate transporter Jen 1 and of the hexose transporters Hxt1, Hxt3 and Hxt6, in response to glucose. Remarkably, Snf1 phosphorylation on Rod1 occurs not only in glucose limitation, but also in the presence of glucose. In this condition, Snf1 phosphorylation inhibits Rod1-mediated trafficking of Hxt1 and Hxt3, thus maintaining a high glucose transporter activity [133]. Therefore, Snf1-mediated phosphorylation has both an inhibitory and activatory function on the trafficking of hexose transporters, depending on the level of Snf1-mediated phosphorylation on Rod1 [133]. According to the proposed model, when Snf1 activity is high, Rod1 is hyper-phosphorylated and the endocytosis of hexose transporters is active. On the other hand, in glucose growing cells, Snf1 activity is low, Rod1 is hypo-phosphorylated and thus its trafficking function is inhibited, indicating that Snf1 retains physiologically important function also under high-glucose conditions, probably to direct its activity to specific targets [133].

Snf1 also regulates Arf3 [134], one of the ADP-ribosylation factors (Arfs), involved in vesicle transport and actin reorganization. Yeast Arf3 is required for invasive growth and its activity is stimulated upon glucose-depletion in a Snf1dependent manner. The regulation of invasive growth in nutrient depletion is actually a conventional role of Snf1 [135, 136]. However, the peculiarity of the activation of Arf3 is that it does not depend on Snf1 kinase activity, but rather on its absolutely new role as a GEF (Guanine Nucleotide Exchange Factor). In fact, it was shown that the C-terminal hydrophobic $\alpha$-helix core of Snf1 is a non-canonical GEF for Arf3 activation [134].

\section{Snf1 and the regulation of cell proliferation, cell cycle and metabolism}

Several reports indicate that Snf1 could be active in the presence of high glucose [54, 133, 137, 138], indicating regulatory roles for Snf1 under glucose repression. In facts, cells lacking Snf1 (both snf1D and snf1as mutant, whose activity can be chemically inhibited) show a slow growth phenotype and 


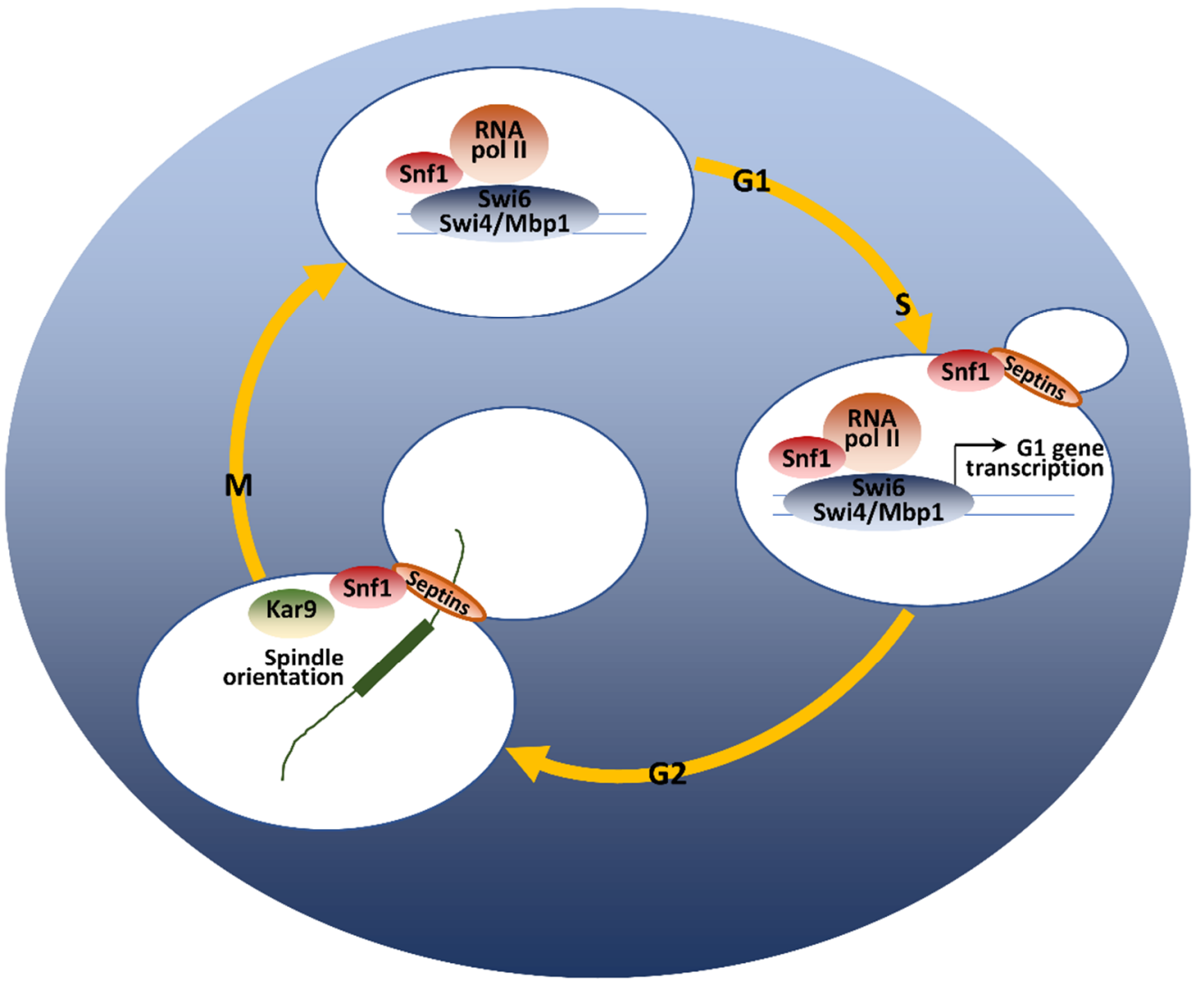

FIGURE 3: A model of the regulatory role of Snf1 during the cell cycle. At the G1/S phase transition, Snf1 promotes the binding of Swi4, Mbp1 and Swi6 proteins to $\mathrm{G} 1$ promoters and favors the proper recruitment of the RNA Polymerase II. From bud emergence, active Snf1 is localized to the bud neck, in a septin-dependent manner. At the metaphase-to-anaphase transition, Snf1, as part of the Kar9-dependent pathway, promotes spindle alignment along the mother-bud axis and guarantees proper nuclei segregation during mitosis. See text for details.

an increased fraction of cells in $\mathrm{G} 1$ phase, in synthetic medium supplemented with $2 \%$ glucose $[25,139]$. Nevertheless, no perturbations of growth occur in complete (YPD, with $2 \%$ glucose) and in synthetic media with $5 \%$ glucose $[25,139]$, as well as in complete synthetic medium (our unpublished results), indicating that the nutritional composition of the media may influence the cellular requirement for Snf1 function.

The relevant role of the catalytic activity of Snf1 in regulating proliferation in glucose-repressed condition is further supported by the fact that Snf1 loss reduces the expression of G1-specific genes [139]. The G1/S transition is regulated by the expression of about 150 genes (the G1 regulon) [140], controlled by the transcription factors SBF (Swi4-Swi6) and MBF (Mbp1-Swi6) [67]. Snf1 directs the expression of both SBF and MBF-regulated genes $[25,139]$, by modulating the recruitment of both the co-activator Swi6 and the RNA polymerase II to the promoters of G1-genes [139] (Fig. 3).

Snf1-T210 is weakly phosphorylated in $2 \%$ glucose, confirming that it is partially active in that growth condition [21, $139,141]$. Consistently, the non phosphorylatable SNF1T210A mutant shows a slow growth phenotype and a delayed G1/S transition. [25, 139].
Snf1 exerts its function in mitosis too and active Snf1 is localized at the division site from the time of bud emergence to cytokinesis [142]. Both septins and protein kinase Elm1 are required for proper Snf1 localization to the bud neck, indicating that the presence of an accurate scaffold is necessary for this process (Fig. 3). Loss of Snf1 activity causes a defect in the correct alignment of the mitotic spindle, that in turn induces a delay of the metaphase-to-anaphase transition, thus clearly indicating Snf1 function for proper spindle orientation. Two major pathways are responsible for the spindle alignment along the mother-bud axis in budding yeast: the Kar9-pathway and the Dyn1-pathway [143]. Recent results show that Snf1 acts in parallel to Dyn1 and in concert with Kar9 to promote spindle positioning, probably phosphorylating components of the Kar9-dependent pathway [142]. In support of these data, several key regulators of cell cycle are known interactors of Snf1, mainly involved in the network of spindle orientation, mitotic exit and cytokinesis (Fig. 2).

It is amazing that cells lacking Snf1 and growing in synthetic media containing $2 \%$ glucose, show an extensive transcriptional reprogramming, being the most upregulated genes mainly involved in transmembrane transport and 
metabolic processes such as aminoacid biosynthesis, iron homeostasis and redox metabolism [144]. Moreover, an increase of cellular dependence on mitochondrial function in glucose repression condition is clearly noticeable in snf1 $\Delta$ cells, further supporting the emerging roles of Snf1 in nonlimiting nutrient condition too [144].

\section{PERSPECTIVES AND CONCLUDING REMARKS}

Many studies have reported that AMPK activity is altered in several diseases, such as inflammation, diabetes and cancer $[145,146]$. Moreover, the number of pharmacological agents that activate AMPK has continued to increase and some of them are promise hypoglycemic agents. Importantly, although AMPK is considered a key target for cancer treatment, emerging data indicate that AMPK performs both anti- and pro-tumorigenic roles depending on the composition of AMPK complex, signaling networks and environmental conditions [147, 148]. The pro-tumorigenic role of AMPK involves promotion of metabolic adaptation for cancer cell survival by regulating fatty acid metabolism and maintaining the ability to growth in stressful conditions $[145,149]$.

Therefore, the expansion of the repertoire of AMPK substrates, as well as more in-depth studies of the molecular mechanisms by which AMPK is activated, will help to better understand the roles of this kinase in the regulation of human pathologies. In this context, the yeast unicellular

\section{REFERENCES}

1. Herzig S, and Shaw RJ (2018). AMPK: guardian of metabolism and mitochondrial homeostasis. Nat Rev Mol Cell Biol 19(2): 121-135. doi: 10.1038/nrm.2017.95

2. Ghillebert R, Swinnen E, Wen J, Vandesteene L, Ramon M, Norga $\mathrm{K}$, Rolland F, and Winderickx J (2011). The AMPK/SNF1/SnRK1 fuel gauge and energy regulator: structure, function and regulation. FEBS J 278(21): 3978-90. doi: 10.1111/j.1742-4658.2011.08315.x

3. Hedbacker K, and Carlson M (2008). SNF1/AMPK pathways in yeast. Front Biosci 13: 2408-20. doi: 10.2741/2854

4. Carlson M, Osmond BC, and Botstein D (1981). Mutants of yeast defective in sucrose utilization. Genetics 98(1): 25-40. PMID: 7040163

5. Rudolph MJ, Amodeo GA, Bai Y, and Tong L (2005). Crystal structure of the protein kinase domain of yeast AMP-activated protein kinase Snf1. Biochem Biophys Res Commun 337(4): 12248. doi: 10.1016/j.bbrc.2005.09.181

6. Chen L, Jiao Z-H, Zheng L-S, Zhang Y-Y, Xie S-T, Wang Z-X, and Wu J-W (2009). Structural insight into the autoinhibition mechanism of AMP-activated protein kinase. Nature 459(7250): 1146-9. doi: 10.1038/nature08075

7. Schmidt MC, and McCartney RR (2000). beta-subunits of Snf1 kinase are required for kinase function and substrate definition. EMBO J 19(18): 4936-43. doi: 10.1093/emboj/19.18.4936

8. Erickson JR, and Johnston M (1993). Genetic and molecular characterization of GAL83: its interaction and similarities with other genes involved in glucose repression in Saccharomyces organism Saccharomyces cerevisiae is a powerful model for studying fundamental aspects of eukaryotic cell biology and to validate the increasing downstream targets of the class of Snf1/AMPK protein kinases which control the complexity of cellular physiology.

\section{ACKNOWLEDGEMENTS}

Work in the authors' laboratory was supported by SysBioNet project, a MIUR initiative from the Italian Roadmap of European Strategy Forum on Research Infrastructures (ESFRI). F.T. has been supported by fellowships from MIUR, R.N. was funded by a fellowship from SysBioNet.

\section{CONFLICT OF INTEREST}

The authors have no conflicts of interest to declare.

\section{COPYRIGHT}

C 2018 Coccetti et al. This is an open-access article released under the terms of the Creative Commons Attribution (CC BY) license, which allows the unrestricted use, distribution, and reproduction in any medium, provided the original author and source are acknowledged.

Please cite this article as: Paola Coccetti, Raffaele Nicastro and Farida Tripodi (2018). Conventional and emerging roles of the energy sensor Snf1/AMPK in Saccharomyces cerevisiae. Microbial Cell 5(11): 482-494. doi: 10.15698/mic2018.11.655

cerevisiae. Genetics 135(3): 655-64. PMID: 8293971

9. Yang $X$, Jiang $R$, and Carlson $M$ (1994). A family of proteins containing a conserved domain that mediates interaction with the yeast SNF1 protein kinase complex. EMBO J 13(24): 5878-86. PMID: 7813428

10. Jiang R, and Carlson M (1997). The Snf1 protein kinase and its activating subunit, Snf4, interact with distinct domains of the Sip1/Sip2/Gal83 component in the kinase complex. Mol Cell Biol 17(4): 2099-106. 9121458. doi: 10.1128/MCB.17.4.2099

11. Vincent O, Townley R, Kuchin S, and Carlson M (2001). Subcellular localization of the Snf1 kinase is regulated by specific beta subunits and a novel glucose signaling mechanism. Genes Dev 15(9): 1104-14. doi: 10.1101/gad.879301

12. Hedbacker K, Townley R, and Carlson M (2004). Cyclic AMPdependent protein kinase regulates the subcellular localization of Snf1-Sip1 protein kinase. Mol Cell Biol 24(5): 1836-43. PMID: 14966266

13. Nath N, McCartney RR, and Schmidt MC (2002). Purification and characterization of Snf1 kinase complexes containing a defined Beta subunit composition. J Biol Chem 277(52): 50403-8. doi: 10.1074/jbc.M207058200

14. Ashrafi K, Lin SS, Manchester JK, and Gordon JI (2000). Sip2p and its partner snf1p kinase affect aging in S. cerevisiae. Genes Dev 14(15): 1872-85. doi: 10.1101/gad.14.15.1872

15. Hedbacker $\mathrm{K}$, and Carlson $\mathrm{M}$ (2006). Regulation of the nucleocytoplasmic distribution of Snf1-Gal83 protein kinase. 


\section{Eukaryot Cell 5(12): 1950-6. doi: 10.1128/EC.00256-06}

16. Vincent O, and Carlson M (1999). Gal83 mediates the interaction of the Snf1 kinase complex with the transcription activator Sip4. EMBO J 18(23): 6672-81. doi: 10.1093/emboj/18.23.6672

17. Kuchin S, Treich I, and Carlson M (2000). A regulatory shortcut between the Snf1 protein kinase and RNA polymerase II holoenzyme. Proc Natl Acad Sci U S A 97(14): 7916-20. doi: 10.1073/pnas.140109897

18. Momcilovic M, Iram SH, Liu Y, and Carlson M (2008). Roles of the glycogen-binding domain and Snf4 in glucose inhibition of SNF1 protein kinase. J Biol Chem 283(28): 19521-9. doi: 10.1074/jbc.M803624200

19. Celenza JL, and Carlson M (1989). Mutational analysis of the Saccharomyces cerevisiae SNF1 protein kinase and evidence for functional interaction with the SNF4 protein. Mol Cell Biol 9(11): 5034-44. doi: 10.1128/MCB.9.11.5034

20. Leech A, Nath N, McCartney RR, and Schmidt MC (2003). Isolation of mutations in the catalytic domain of the snf1 kinase that render its activity independent of the snf4 subunit. Eukaryot Cell 2(2): 265-73. doi: 10.1128/EC.2.2.265-273.2003

21. McCartney RR, and Schmidt MC (2001). Regulation of Snf1 kinase. Activation requires phosphorylation of threonine 210 by an upstream kinase as well as a distinct step mediated by the Snf4 subunit. J Biol Chem 276(39): 36460-6. doi: 10.1074/jbc.M104418200

22. Hong S-P, Leiper FC, Woods A, Carling D, and Carlson M (2003). Activation of yeast Snf1 and mammalian AMP-activated protein kinase by upstream kinases. Proc Natl Acad Sci U S A 100(15): 883943. doi: 10.1073/pnas.1533136100

23. Sutherland CM, Hawley SA, McCartney RR, Leech A, Stark MJR, Schmidt MC, and Hardie DG (2003). Elm1p is one of three upstream kinases for the Saccharomyces cerevisiae SNF1 complex. Curr Biol 13(15): 1299-305. doi: 10.1016/S0960-9822(03)00459-7

24. Dubacq C, Chevalier A, and Mann C (2004). The protein kinase Snf1 is required for tolerance to the ribonucleotide reductase inhibitor hydroxyurea. Mol Cell Biol 24(6): 2560-72. doi: 10.1128/MCB.24.6.2560-2572.2004

25. Pessina S, Tsiarentsyeva V, Busnelli S, Vanoni M, Alberghina L, and Coccetti $P$ (2010). Snf1/AMPK promotes S-phase entrance by controlling CLB5 transcription in budding yeast. Cell Cycle 9(11): 2189-200. doi: 10.4161/cc.9.11.11847

26. Portillo F, Mulet JM, and Serrano R (2005). A role for the nonphosphorylated form of yeast Snf1: tolerance to toxic cations and activation of potassium transport. FEBS Lett 579(2): 512-6. doi: 10.1016/j.febslet.2004.12.019

27. Shinoda J, and Kikuchi Y (2007). Rod1, an arrestin-related protein, is phosphorylated by Snf1-kinase in Saccharomyces cerevisiae. Biochem Biophys Res Commun 364(2): 258-63. doi: 10.1016/j.bbrc.2007.09.134

28. Wade SL, Poorey K, Bekiranov S, and Auble DT (2009). The Snf1 kinase and proteasome-associated Rad23 regulate UV-responsive gene expression. EMBO J 28(19): 2919-31. doi: 10.1038/emboj.2009.229

29. Nicastro R, Tripodi F, Gaggini M, Castoldi A, Reghellin V, Nonnis $S$, Tedeschi G, and Coccetti $P$ (2015). Snf1 phosphorylates adenylate cyclase and negatively regulates protein kinase A- dependent transcription in Saccharomyces cerevisiae. J Biol Chem 290(41): 24715-24726. doi: 10.1074/jbc.M115.658005

30. Ludin K, Jiang R, and Carlson M (1998). Glucose-regulated interaction of a regulatory subunit of protein phosphatase 1 with the Snf1 protein kinase in Saccharomyces cerevisiae. Proc Natl Acad Sci U S A 95(11): 6245-50. doi: 10.1073/pnas.95.11.6245

31. Sanz P, Alms GR, Haystead TA, and Carlson M (2000). Regulatory interactions between the Reg1-Glc7 protein phosphatase and the Snf1 protein kinase. Mol Cell Biol 20(4): 1321-8. doi: 10.1128/MCB.20.4.1321-1328.2000

32. Frederick DL, and Tatchell K (1996). The REG2 gene of Saccharomyces cerevisiae encodes a type 1 protein phosphatasebinding protein that functions with Reg1p and the Snf1 protein kinase to regulate growth. Mol Cell Biol 16(6): 2922-31. doi: 10.1128/MCB.16.6.2922

33. Huang D, Farkas I, and Roach PJ (1996). Pho85p, a cyclindependent protein kinase, and the Snf1p protein kinase act antagonistically to control glycogen accumulation in Saccharomyces cerevisiae. Mol Cell Biol 16(8): 4357-65. doi: 10.1128/MCB.16.8.4357

34. Rubenstein EM, McCartney RR, Zhang C, Shokat KM, Shirra MK, Arndt KM, and Schmidt MC (2008). Access denied: Snf1 activation loop phosphorylation is controlled by availability of the phosphorylated threonine 210 to the PP1 phosphatase. J Biol Chem 283(1): 222-30. doi: 10.1074/jbc.M707957200

35. Dale S, Wilson WA, Edelman AM, and Hardie DG (1995). Similar substrate recognition motifs for mammalian AMP-activated protein kinase, higher plant HMG-CoA reductase kinase-A, yeast SNF1, and mammalian calmodulin-dependent protein kinase I. FEBS Lett 361(2-3): 191-5. doi: 10.1016/0014-5793(95)00172-6

36. Wilson WA, Hawley SA, and Hardie DG (1996). Glucose repression/derepression in budding yeast: SNF1 protein kinase is activated by phosphorylation under derepressing conditions, and this correlates with a high AMP:ATP ratio. Curr Biol 6(11): 1426-34. doi: 10.1016/S0960-9822(96)00747-6

37. Mayer F V, Heath R, Underwood E, Sanders MJ, Carmena D, McCartney RR, Leiper FC, Xiao B, Jing C, Walker PA, Haire LF, Ogrodowicz R, Martin SR, Schmidt MC, Gamblin SJ, and Carling D (2011). ADP regulates SNF1, the Saccharomyces cerevisiae homolog of AMP-activated protein kinase. Cell Metab 14(5): 70714. doi: 10.1016/j.cmet.2011.09.009

38. Chandrashekarappa DG, McCartney RR, and Schmidt MC (2011). Subunit and domain requirements for adenylate-mediated protection of Snf1 kinase activation loop from dephosphorylation. J Biol Chem 286(52): 44532-41. doi: 10.1074/jbc.M111.315895

39. Nayak V, Zhao K, Wyce A, Schwartz MF, Lo W-S, Berger SL, and Marmorstein $R$ (2006). Structure and dimerization of the kinase domain from yeast Snf1, a member of the Snf1/AMPK protein family. Structure 14(3): 477-85. doi: 10.1016/j.str.2005.12.008

40. McCartney RR, Garnar-Wortzel L, Chandrashekarappa DG, and Schmidt MC (2016). Activation and inhibition of Snf1 kinase activity by phosphorylation within the activation loop. Biochim Biophys Acta - Proteins Proteomics 1864(11): 1518-1528. doi: 10.1016/j.bbapap.2016.08.007

41. Simpson-Lavy KJ, and Johnston M (2013). SUMOylation regulates the SNF1 protein kinase. Proc Natl Acad Sci U S A 110(43): 17432-7. doi: 10.1073/pnas. 1304839110

42. Wilson MA, Koutelou E, Hirsch C, Akdemir K, Schibler A, Barton 
MC, and Dent SYR (2011). Ubp8 and SAGA Regulate Snf1 AMP Kinase Activity. Mol Cell Biol 31(15): 3126-3135. doi: 10.1128/MCB.01350-10

43. Jiao R, Postnikoff S, Harkness TA, and Arnason TG (2015). The SNF1 Kinase Ubiquitin-associated Domain Restrains Its Activation, Activity, and the Yeast Life Span. J Biol Chem 290(25): 15393-404. doi: 10.1074/jbc.M115.647032

44. Sharifpoor $S$, Nguyen Ba AN, Youn J-Y, Young J-Y, van Dyk D, Friesen H, Douglas AC, Kurat CF, Chong YT, Founk K, Moses AM, and Andrews BJ (2011). A quantitative literature-curated gold standard for kinase-substrate pairs. Genome Biol 12(4): R39. doi: 10.1186/gb-2011-12-4-r39

45. Cline MS et al. (2007). Integration of biological networks and gene expression data using Cytoscape. Nat Protoc 2(10): 2366-82. doi: 10.1038/nprot.2007.324

46. Young ET, Zhang C, Shokat KM, Parua PK, and Braun KA (2012). The AMP-activated protein kinase Snf1 regulates transcription factor binding, RNA Polymerase II activity and mRNA stability of glucose-repressed genes in Saccharomyces cerevisiae. J Biol Chem 287(34): 29021-34. doi: 10.1074/jbc.M112.380147

47. Hedges D, Proft M, and Entian KD (1995). CAT8, a new zinc cluster-encoding gene necessary for derepression of gluconeogenic enzymes in the yeast Saccharomyces cerevisiae. Mol Cell Biol 15(4): 1915-22. doi: 10.1128/MCB.15.4.1915

48. Treitel MA, Kuchin S, and Carlson M (1998). Snf1 protein kinase regulates phosphorylation of the Mig1 repressor in Saccharomyces cerevisiae. Mol Cell Biol 18(11): 6273-80. doi: 10.1128/MCB.18.11.6273

49. Lesage $P$, Yang $X$, and Carlson M (1996). Yeast SNF1 protein kinase interacts with SIP4, a C6 zinc cluster transcriptional activator: a new role for SNF1 in the glucose response. Mol Cell Biol 16(5): 1921-8. doi: 10.1128/MCB.16.5.1921

50. Lo WS, Duggan L, Emre NC, Belotserkovskya R, Lane WS, Shiekhattar R, and Berger SL (2001). Snf1--a histone kinase that works in concert with the histone acetyltransferase Gcn5 to regulate transcription. Science 293(5532): 1142-6. doi: 10.1126/science.1062322

51. Nehlin JO, and Ronne H (1990). Yeast MIG1 repressor is related to the mammalian early growth response and Wilms' tumour finger proteins. EMBO J 9(9): 2891-8. PMID: 2167835

52. DeVit MJ, and Johnston M (1999). The nuclear exportin Msn5 is required for nuclear export of the Mig1 glucose repressor of Saccharomyces cerevisiae. Curr Biol 9: 1231-1241. doi: 10.1016/S0960-9822(99)80503-X

53. Papamichos-Chronakis M, Gligoris $T$, and Tzamarias D (2004). The Snf1 kinase controls glucose repression in yeast by modulating interactions between the Mig1 repressor and the Cyc8-Tup1 corepressor. EMBO Rep 5(4): 368-372. doi: 10.1038/sj.embor.7400120

54. Ahuatzi D, Riera A, Peláez R, Herrero P, and Moreno F (2007). $\mathrm{Hxk} 2$ regulates the phosphorylation state of Mig1 and therefore its nucleocytoplasmic distribution. J Biol Chem 282(7): 4485-93. doi: 10.1074/jbc.M606854200

55. Ostergaard S, Walløe KO, Gomes SG, Olsson L, and Nielsen J (2001). The impact of GAL6, GAL80, and MIG1 on glucose control of the GAL system in Saccharomyces cerevisiae. FEMS Yeast Res 1(1): 47-55. doi: 10.1111/j.1567-1364.2001.tb00012.x
56. van Oevelen CJC, van Teeffelen HAAM, van Werven FJ, and Timmers HTM (2006). Snf1p-dependent Spt-Ada-Gcn5acetyltransferase (SAGA) recruitment and chromatin remodeling activities on the HXT2 and HXT4 promoters. J Biol Chem 281(7): 4523-31. doi: 10.1074/jbc.M509330200

57. Hohmann S, Van Dijck P, Luyten K, and Thevelein JM (1994). The byp1-3 allele of the Saccharomyces cerevisiae GGS1/TPS1 gene and its multi-copy suppressor tRNA(GLN) (CAG): Ggs1/Tps1 protein levels restraining growth on fermentable sugars and trehalose accumulation. Curr Genet 26(4): 295-301. PMID: 7882422

58. Jin C, Barrientos A, Epstein CB, Butow RA, and Tzagoloff A (2007). SIT4 regulation of Mig1p-mediated catabolite repression in Saccharomyces cerevisiae. FEBS Lett 581(29): 5658-63. doi: 10.1016/j.febslet.2007.11.027

59. Vincent O, and Carlson M (1998). Sip4, a Snf1 kinase-dependent transcriptional activator, binds to the carbon source-responsive element of gluconeogenic genes. EMBO J 17(23): 7002-8. doi: 10.1093/emboj/17.23.7002

60. Randez-Gil F, Bojunga N, Proft M, and Entian KD (1997). Glucose derepression of gluconeogenic enzymes in Saccharomyces cerevisiae correlates with phosphorylation of the gene activator Cat8p. Mol Cell Biol 17(5): 2502-10. doi: 10.1128/MCB.17.5.2502

61. Young ET, Kacherovsky N, and Van Riper K (2002). Snf1 protein kinase regulates Adr1 binding to chromatin but not transcription activation. J Biol Chem 277(41): 38095-103. doi: 10.1074/jbc.M206158200

62. Kacherovsky N, Tachibana C, Amos E, Fox D, and Young ET (2008). Promoter binding by the Adr1 transcriptional activator may be regulated by phosphorylation in the DNA-binding region. PLoS One 3(9): e3213. doi: 10.1371/journal.pone.0003213

63. Shirra MK, McCartney RR, Zhang C, Shokat KM, Schmidt MC, and Arndt KM (2008). A chemical genomics study identifies Snf1 as a repressor of GCN4 translation. J Biol Chem 283(51): 35889-98. doi: 10.1074/jbc.M805325200

64. Abate G, Bastonini E, Braun KA, Verdone L, Young ET, and Caserta M (2012). Snf1/AMPK regulates Gcn5 occupancy, H3 acetylation and chromatin remodelling at $\mathrm{S}$. cerevisiae ADY2 promoter. Biochim Biophys Acta 1819(5): 419-27. doi: 10.1016/j.bbagrm.2012.01.009

65. Shirra MK, Patton-Vogt J, Ulrich A, Liuta-Tehlivets O, Kohlwein SD, Henry SA, and Arndt KM (2001). Inhibition of acetyl coenzyme A carboxylase activity restores expression of the INO1 gene in a snf1 mutant strain of Saccharomyces cerevisiae. Mol Cell Biol 21(17): 5710-22. doi: 10.1128/MCB.21.17.5710-5722.2001

66. Hofbauer HF, Schopf FH, Schleifer H, Knittelfelder OL, Pieber B, Rechberger GN, Wolinski H, Gaspar ML, Kappe CO, Stadlmann J, Mechtler K, Zenz A, Lohner K, Tehlivets O, Henry SA, and Kohlwein SD (2014). Regulation of Gene Expression through a Transcriptional Repressor that Senses Acyl-Chain Length in Membrane Phospholipids. Dev Cell 29(6): 729-39. doi: 10.1016/j.devcel.2014.04.025

67. Koch C, Moll T, Neuberg M, Ahorn H, and Nasmyth K (1993). A role for the transcription factors Mbp1 and Swi4 in progression from G1 to S phase. Science 261(5128): 1551-7. doi: 10.1126/science. 8372350

68. Zhang M, Galdieri L, and Vancura A (2013). The yeast AMPK homolog SNF1 regulates acetyl coenzyme $A$ homeostasis and histone acetylation. Mol Cell Biol 33(23): 4701-17. doi: 


\subsection{8/MCB.00198-13}

69. Benanti JA, Cheung SK, Brady MC, and Toczyski DP (2007). A proteomic screen reveals SCFGrr1 targets that regulate the glycolytic-gluconeogenic switch. Nat Cell Biol 9(10): 1184-91. doi: 10.1038/ncb1639

70. Lee YJ, Jeschke GR, Roelants FM, Thorner J, and Turk BE (2012). Reciprocal phosphorylation of yeast glycerol-3-phosphate dehydrogenases in adaptation to distinct types of stress. Mol Cell Biol 32(22): 4705-17. doi: 10.1128/МСB.00897-12

71. Conrad M, Schothorst J, Kankipati HN, Van Zeebroeck G, RubioTexeira $M$, and Thevelein JM (2014). Nutrient sensing and signaling in the yeast Saccharomyces cerevisiae. FEMS Microbiol Rev 38(2): 254-299. doi: 10.1111/1574-6976.12065

72. Deprez M-A, Eskes E, Wilms T, Ludovico P, and Winderickx J (2018). pH homeostasis links the nutrient sensing PKA/TORC1/Sch9 ménage-à-trois to stress tolerance and longevity. Microb Cell 5(3): 119-136. doi: 10.15698/mic2018.03.618

73. Busti S, Coccetti P, Alberghina L, and Vanoni M (2010). Glucose Signaling-Mediated Coordination of Cell Growth and Cell Cycle in Saccharomyces Cerevisiae. Sensors 10(6): 6195-6240. doi: 10.3390/s100606195

74. Zaman S, Lippman SI, Zhao X, and Broach JR (2008). How Saccharomyces responds to nutrients. Annu Rev Genet 42: 27-81. doi: 10.1146/annurev.genet.41.110306.130206

75. Shashkova S, Welkenhuysen N, and Hohmann S (2015). Molecular communication: crosstalk between the Snf1 and other signaling pathways. FEMS Yeast Res 15(4): fov026. doi: 10.1093/femsyr/fov026

76. Cherry JR, Johnson TR, Dollard C, Shuster JR, and Denis CL (1989). Cyclic AMP-dependent protein kinase phosphorylates and inactivates the yeast transcriptional activator ADR1. Cell 56(3): 409-19. doi: 10.1016/0092-8674(89)90244-4

77. Ratnakumar S, Kacherovsky N, Arms E, and Young ET (2009). Snf1 controls the activity of adr1 through dephosphorylation of Ser230. Genetics 182(3): 735-45. doi: 10.1534/genetics.109.103432

78. De Wever V, Reiter W, Ballarini A, Ammerer G, and Brocard C (2005). A dual role for PP1 in shaping the Msn2-dependent transcriptional response to glucose starvation. EMBO J 24(23): 4115-23. doi: 10.1038/sj.emboj.7600871

79. Barrett L, Orlova M, Maziarz M, and Kuchin S (2012). Protein kinase A contributes to the negative control of Snf1 protein kinase in Saccharomyces cerevisiae. Eukaryot Cell 11(2): 119-28. doi: 10.1128/EC.05061-11

80. Kim D-H, Sarbassov DD, Ali SM, King JE, Latek RR, ErdjumentBromage $H$, Tempst $P$, and Sabatini DM (2002). mTOR interacts with raptor to form a nutrient-sensitive complex that signals to the cell growth machinery. Cell 110(2): 163-75. doi: 10.1016/S00928674(02)00808-5

81. Loewith R, Jacinto E, Wullschleger S, Lorberg A, Crespo JL, Bonenfant $D$, Oppliger $W$, Jenoe $P$, and Hall MN (2002). Two TOR complexes, only one of which is rapamycin sensitive, have distinct roles in cell growth control. Mol Cell 10(3): 457-68. doi: 10.1016/S1097-2765(02)00636-6

82. Wullschleger $S$, Loewith $R$, and Hall MN (2006). TOR signaling in growth and metabolism. Cell 124(3): 471-84. doi: 10.1016/j.cell.2006.01.016
83. Sabatini DM (2006). mTOR and cancer: insights into a complex relationship. Nat Rev Cancer 6(9): 729-734. doi: 10.1038/nrc1974

84. González A, and Hall MN (2017). Nutrient sensing and TOR signaling in yeast and mammals. EMBO J 36(4): 397-408. doi: 10.15252/embj.201696010

85. Reinke A, Anderson S, McCaffery JM, Yates J, Aronova S, Chu S, Fairclough S, Iverson C, Wedaman KP, and Powers T (2004). TOR complex 1 includes a novel component, Tco89p (YPL180w), and cooperates with Ssd1p to maintain cellular integrity in Saccharomyces cerevisiae. J Biol Chem 279(15): 14752-62. doi: 10.1074/jbc.M313062200

86. Wedaman KP, Reinke A, Anderson S, Yates J, McCaffery JM, and Powers $T$ (2003). Tor kinases are in distinct membrane-associated protein complexes in Saccharomyces cerevisiae. Mol Biol Cell 14(3): 1204-20. doi: 10.1091/mbc.E02-09-0609

87. Nojima H, Tokunaga C, Eguchi S, Oshiro N, Hidayat S, Yoshino K, Hara K, Tanaka N, Avruch J, and Yonezawa K (2003). The mammalian target of rapamycin (mTOR) partner, raptor, binds the mTOR substrates p70 S6 kinase and 4E-BP1 through their TOR signaling (TOS) motif. J Biol Chem 278(18): 15461-4. doi: 10.1074/jbc.C200665200

88. Schalm SS, Fingar DC, Sabatini DM, and Blenis J (2003). TOS motif-mediated raptor binding regulates 4E-BP1 multisite phosphorylation and function. Curr Biol 13(10): 797-806. doi: 10.1016/S0960-9822(03)00329-4

89. Hara $\mathrm{K}$, Maruki $\mathrm{Y}$, Long $\mathrm{X}$, Yoshino $\mathrm{K}$, Oshiro $\mathrm{N}$, Hidayat $\mathrm{S}$, Tokunaga C, Avruch J, and Yonezawa K (2002). Raptor, a binding partner of target of rapamycin (TOR), mediates TOR action. Cell 110(2): 177-89. doi: 10.1016/S0092-8674(02)00833-4

90. Hughes Hallett JE, Luo X, and Capaldi AP (2015). Snf1/AMPK promotes the formation of Kog1/Raptor-bodies to increase the activation threshold of TORC1 in budding yeast. Elife 4: e09181. doi: 10.7554/eLife.09181

91. Urban J, Soulard A, Huber A, Lippman S, Mukhopadhyay D, Deloche O, Wanke V, Anrather D, Ammerer G, Riezman H, Broach $J R$, De Virgilio C, Hall MN, and Loewith R (2007). Sch9 is a major target of TORC1 in Saccharomyces cerevisiae. Mol Cell 26(5): 66374. doi: 10.1016/j.molcel.2007.04.020

92. Huber A, French SL, Tekotte H, Yerlikaya S, Stahl M, Perepelkina MP, Tyers M, Rougemont J, Beyer AL, and Loewith R (2011). Sch9 regulates ribosome biogenesis via Stb3, Dot6 and Tod6 and the histone deacetylase complex RPD3L. EMBO J 30(15): 3052-3064. doi: 10.1038/emboj.2011.221

93. Jorgensen P, Rupes I, Sharom JR, Schneper L, Broach JR, and Tyers $M$ (2004). A dynamic transcriptional network communicates growth potential to ribosome synthesis and critical cell size. Genes Dev 18(20): 2491-505. doi: 10.1101/gad.1228804

94. Lu J-Y, Lin Y-Y, Sheu J-C, Wu J-T, Lee F-J, Chen Y, Lin M-I, Chiang F-T, Tai T-Y, Berger SL, Zhao Y, Tsai K-S, Zhu H, Chuang L-M, and Boeke JD (2011). Acetylation of yeast AMPK controls intrinsic aging independently of caloric restriction. Cell 146(6): 969-79. doi: 10.1016/j.cell.2011.07.044

95. DeMille D, Badal BD, Evans JB, Mathis AD, Anderson JF, and Grose JH (2015). PAS kinase is activated by direct SNF1-dependent phosphorylation and mediates inhibition of TORC1 through the phosphorylation and activation of Pbp1. Mol Biol Cell 26(3): 569582. doi: 10.1091/mbc.e14-06-1088

96. Hughes Hallett JE, Luo X, and Capaldi AP (2014). State 
Transitions in the TORC1 Signaling Pathway and Information Processing in Saccharomyces cerevisiae. Genetics 198(2): 773-786. doi: 10.1534/genetics.114.168369

97. Orlova M, Kanter E, Krakovich D, and Kuchin S (2006). Nitrogen availability and TOR regulate the Snf1 protein kinase in Saccharomyces cerevisiae. Eukaryot Cell 5(11): 1831-7. doi: 10.1128/EC.00110-06

98. Nakatogawa H, Suzuki K, Kamada $Y$, and Ohsumi $Y$ (2009). Dynamics and diversity in autophagy mechanisms: lessons from yeast. Nat Rev Mol Cell Biol 10(7): 458-467. doi: 10.1038/nrm2708

99. Reggiori F, and Klionsky DJ (2013). Autophagic Processes in Yeast: Mechanism, Machinery and Regulation. Genetics 194(2): 341-361. doi: 10.1534/genetics.112.149013

100. Kamada Y (2010). Prime-numbered Atg proteins act at the primary step in autophagy: unphosphorylatable Atg13 can induce autophagy without TOR inactivation. Autophagy 6(3): 415-6. doi: 10.4161/auto.6.3.11390

101. Wang Z, Wilson WA, Fujino MA, and Roach PJ (2001). Antagonistic controls of autophagy and glycogen accumulation by Snf1p, the yeast homolog of AMP-activated protein kinase, and the cyclin-dependent kinase Pho85p. Mol Cell Biol 21(17): 5742-52. doi: 10.1128/MCB.21.17.5742-5752.2001

102. Yi C, Tong J, Lu $P$, Wang $Y$, Zhang J, Sun $C$, Yuan $K$, Xue R, Zou B, Li N, Xiao S, Dai C, Huang Y, Xu L, Li L, Chen S, Miao D, Deng H, Li $H$, and $Y u L$ (2017). Formation of a Snf1-Mec1-Atg1 Module on Mitochondria Governs Energy Deprivation-Induced Autophagy by Regulating Mitochondrial Respiration. Dev Cell 41(1): 59-71.e4. doi: 10.1016/j.devcel.2017.03.007

103. Thorsen M, Perrone GG, Kristiansson E, Traini M, Ye T, Dawes IW, Nerman O, and Tamás MJ (2009). Genetic basis of arsenite and cadmium tolerance in Saccharomyces cerevisiae. BMC Genomics 10(1): 105. doi: 10.1186/1471-2164-10-105

104. Pérez-Sampietro M, Casas $C$, and Herrero E (2013). The AMPK family member Snf1 protects Saccharomyces cerevisiae cells upon glutathione oxidation. PLoS One 8(3): e58283. doi: 10.1371/journal.pone.0058283

105. Li L, Kaplan J, and Ward DM (2017). The glucose sensor Snf1 and the transcription factors Msn2 and Msn4 regulate transcription of the vacuolar iron importer gene CCC1 and iron resistance in yeast. J Biol Chem 292(37): 15577-15586. doi: 10.1074/jbc.M117.802504

106. Hong S-P, and Carlson M (2007). Regulation of snf1 protein kinase in response to environmental stress. J Biol Chem 282(23): 16838-45. doi: 10.1074/jbc.M700146200

107. Hahn J-S, and Thiele DJ (2004). Activation of the Saccharomyces cerevisiae heat shock transcription factor under glucose starvation conditions by Snf1 protein kinase. J Biol Chem 279(7): 5169-76. doi: 10.1074/jbc.M311005200

108. Platara M, Ruiz A, Serrano R, Palomino A, Moreno F, and Ariño $J$ (2006). The transcriptional response of the yeast $\mathrm{Na}(+)$-ATPase ENA1 gene to alkaline stress involves three main signaling pathways. J Biol Chem 281(48): 36632-42. doi: 10.1074/jbc.M606483200

109. Mori K (2009). Signalling pathways in the unfolded protein response: development from yeast to mammals. J Biochem 146(6): 743-50. doi: 10.1093/jb/mvp166

110. Walter P, and Ron D (2011). The Unfolded Protein Response:
From Stress Pathway to Homeostatic Regulation. Science 334(6059): 1081-1086. doi: 10.1126/science.1209038

111. Ferrer-Dalmau J, Randez-Gil F, Marquina M, Prieto JA, and Casamayor A (2015). Protein kinase Snf1 is involved in the proper regulation of the unfolded protein response in Saccharomyces cerevisiae. Biochem J 468(1): 33-47. doi: 10.1042/BJ20140734

112. Mizuno $T$, Masuda $Y$, and Irie $K$ (2015). The Saccharomyces cerevisiae AMPK, Snf1, Negatively Regulates the Hog1 MAPK Pathway in ER Stress Response. PLOS Genet 11(9): e1005491. doi: 10.1371/journal.pgen.1005491

113. Back SH, Schröder M, Lee K, Zhang K, and Kaufman RJ (2005). ER stress signaling by regulated splicing: IRE1/HAC1/XBP1. Methods 35(4): 395-416. doi: 10.1016/J.YMETH.2005.03.001

114. Simpson-Lavy KJ, Bronstein A, Kupiec $M$, and Johnston $M$ (2015). Cross-Talk between Carbon Metabolism and the DNA Damage Response in S. cerevisiae. Cell Rep 12(11): 1865-75. doi: 10.1016/j.celrep.2015.08.025

115. Salminen A, Kaarniranta K, and Kauppinen A (2016). Agerelated changes in AMPK activation: Role for AMPK phosphatases and inhibitory phosphorylation by upstream signaling pathways. Ageing Res Rev 28: 15-26. doi: 10.1016/j.arr.2016.04.003

116. Friis RMN, Glaves JP, Huan T, Li L, Sykes BD, and Schultz MC (2014). Rewiring AMPK and mitochondrial retrograde signaling for metabolic control of aging and histone acetylation in respiratorydefective cells. Cell Rep 7(2): 565-74. doi: 10.1016/j.celrep.2014.03.029

117. Lorenz DR, Cantor CR, and Collins JJ (2009). A network biology approach to aging in yeast. Proc Natl Acad Sci. 106(4): 1145-1150. doi: 10.1073/pnas.0812551106

118. Apfeld J, O'Connor G, McDonagh T, DiStefano PS, and Curtis R (2004). The AMP-activated protein kinase AAK-2 links energy levels and insulin-like signals to lifespan in C. elegans. Genes Dev 18(24): 3004-3009. doi: 10.1101/gad.1255404

119. Yang S, Long L-H, Li D, Zhang J-K, Jin S, Wang F, and Chen J-G (2015). $\beta$-Guanidinopropionic acid extends the lifespan of Drosophila melanogaster via an AMP-activated protein kinasedependent increase in autophagy. Aging Cell 14(6): 1024-1033. doi: 10.1111/acel.12371

120. Reznick RM, and Shulman GI (2006). The role of AMP-activated protein kinase in mitochondrial biogenesis. J Physiol 574(Pt 1): 339. doi: 10.1113/jphysiol.2006.109512

121. Kim J, Kundu M, Viollet B, and Guan K-L (2011). AMPK and mTOR regulate autophagy through direct phosphorylation of Ulk1. Nat Cell Biol 13(2): 132-41. doi: 10.1038/ncb2152

122. Kim H, Moon SY, Kim J-S, Baek CH, Kim M, Min JY, and Lee SK (2015). Activation of AMP-activated protein kinase inhibits ER stress and renal fibrosis. Am J Physiol Renal Physiol 308(3): F22636. doi: 10.1152/ajprenal.00495.2014

123. Sanli T, Steinberg GR, Singh G, and Tsakiridis T (2014). AMPactivated protein kinase (AMPK) beyond metabolism: a novel genomic stress sensor participating in the DNA damage response pathway. Cancer Biol Ther 15(2): 156-69. doi: 10.4161/cbt.26726

124. Reznick RM, Zong H, Li J, Morino K, Moore IK, Yu HJ, Liu Z-X, Dong J, Mustard KJ, Hawley SA, Befroy D, Pypaert M, Hardie DG, Young LH, and Shulman GI (2007). Aging-Associated Reductions in AMP-Activated Protein Kinase Activity and Mitochondrial Biogenesis. Cell Metab 5(2): 151-156. doi: 


\subsection{6/j.cmet.2007.01.008}

125. Wierman MB, Maqani N, Strickler E, Li M, and Smith JS (2017). Caloric Restriction Extends Yeast Chronological Life Span by Optimizing the Snf1 (AMPK) Signaling Pathway. Mol Cell Biol 37(13): e00562-16. doi: 10.1128/MCB.00562-16

126. Maqani N, Fine RD, Shahid M, Li M, Enriquez-Hesles E, and Smith JS (2018). Spontaneous mutations in CYC8 and MIG1 suppress the short chronological lifespan of budding yeast lacking SNF1/AMPK. Microb Cell 5(5): 233-248. doi: 10.15698/mic2018.05.630

127. Ogawa $T$, Tsubakiyama R, Kanai $M$, Koyama $T$, Fujii $T$, lefuji $H$, Soga T, Kume K, Miyakawa T, Hirata D, and Mizunuma M (2016). Stimulating S-adenosyl-I-methionine synthesis extends lifespan via activation of AMPK. Proc Natl Acad Sci U S A 113(42): 11913-11918. doi: 10.1073/pnas.1604047113

128. López-Otín C, Galluzzi L, Freije JMP, Madeo F, and Kroemer G (2016). Metabolic Control of Longevity. Cell 166(4): 802-821. doi: 10.1016/j.cell.2016.07.031

129. Longo VD, and Fabrizio P (2011). Chronological Aging in Saccharomyces cerevisiae. Subcell Biochem 57: 101-121. doi: 10.1007/978-94-007-2561-4_5

130. Laun $P$, Rinnerthaler $M$, Bogengruber $E$, Heeren $G$, and Breitenbach $M$ (2006). Yeast as a model for chronological and reproductive aging - A comparison. Exp Gerontol 41(12): 12081212. doi: 10.1016/j.exger.2006.11.001

131. Becuwe M, Vieira N, Lara D, Gomes-Rezende J, Soares-Cunha C, Casal M, Haguenauer-Tsapis R, Vincent $O$, Paiva S, and Léon S (2012). A molecular switch on an arrestin-like protein relays glucose signaling to transporter endocytosis. J Cell Biol 196(2): 247259. doi: 10.1083/jcb.201109113

132. Llopis-Torregrosa V, Ferri-Blázquez A, Adam-Artigues A, Deffontaines $E$, van Heusden GPH, and Yenush $L$ (2016). Regulation of the Yeast Hxt6 Hexose Transporter by the Rod1 $\alpha$-Arrestin, the Snf1 Protein Kinase, and the Bmh2 14-3-3 Protein. J Biol Chem 291(29): 14973-14985. doi: 10.1074/jbc.M116.733923

133. O'Donnell AF, McCartney RR, Chandrashekarappa DG, Zhang BB, Thorner J, and Schmidt MC (2015). 2-Deoxyglucose impairs Saccharomyces cerevisiae growth by stimulating Snf1-regulated and $\alpha$-arrestin-mediated trafficking of hexose transporters 1 and 3 . Mol Cell Biol 35(6): 939-55. doi: 10.1128/MCB.01183-14

134. Hsu J-W, Chen K-J, and Lee F-JS (2015). Snf1/AMP-activated protein kinase activates Arf3p to promote invasive yeast growth via a non-canonical GEF domain. Nat Commun 6(1): 7840. doi: $10.1038 /$ ncomms 8840

135. Kuchin S, Vyas VK, and Carlson M (2002). Snf1 protein kinase and the repressors Nrg1 and Nrg2 regulate FLO11, haploid invasive growth, and diploid pseudohyphal differentiation. Mol Cell Biol 22(12): 3994-4000. doi: 10.1128/MCB.22.12.3994-4000.2002

136. Vyas VK, Kuchin S, Berkey CD, and Carlson M (2003). Snf1 kinases with different beta-subunit isoforms play distinct roles in regulating haploid invasive growth. Mol Cell Biol 23(4): 1341-8. doi: 10.1128/MCB.23.4.1341-1348.2003
137. Denis CL (1984). Identification of new genes involved in the regulation of yeast alcohol dehydrogenase II. Genetics 108(4): 83344. PMID: 6392016

138. Galello F, Pautasso C, Reca S, Cañonero L, Portela P, Moreno $S$, and Rossi $S$ (2017). Transcriptional regulation of the protein kinase a subunits in Saccharomyces cerevisiae during fermentative growth. Yeast 34(12): 495-508. doi: 10.1002/yea.3252

139. Busnelli S, Tripodi F, Nicastro R, Cirulli C, Tedeschi G, Pagliarin $R$, Alberghina L, and Coccetti P (2013). Snf1/AMPK promotes SBF and MBF-dependent transcription in budding yeast. Biochim Biophys Acta 1833(12): 3254-64. doi: 10.1016/j.bbamcr.2013.09.014

140. Spellman PT, Sherlock G, Zhang MQ, lyer VR, Anders K, Eisen MB, Brown PO, Botstein D, and Futcher B (1998). Comprehensive identification of cell cycle-regulated genes of the yeast Saccharomyces cerevisiae by microarray hybridization. Mol Biol Cell 9(12): 3273-97. doi: 10.1091/mbc.9.12.3273

141. McCartney RR, Chandrashekarappa DG, Zhang BB, and Schmidt MC (2014). Genetic Analysis of Resistance and Sensitivity to 2-deoxyglucose in Saccharomyces cerevisiae. Genetics 198(2): 635-46. doi: 10.1534/genetics.114.169060

142. Tripodi F, Fraschini $R$, Zocchi $M$, Reghellin $V$, and Coccetti $P$ (2018). Snf1/AMPK is involved in the mitotic spindle alignment in Saccharomyces cerevisiae. Sci Rep 8(1): 5853. doi: 10.1038/s41598-018-24252-y

143. Moore JK, and Cooper JA (2010). Coordinating mitosis with cell polarity: Molecular motors at the cell cortex. Semin Cell Dev Biol 21(3): 283-289. doi: 10.1016/j.semcdb.2010.01.020

144. Nicastro R, Tripodi F, Guzzi C, Reghellin V, Khoomrung S, Capusoni C, Compagno C, Airoldi C, Nielsen J, Alberghina L, and Coccetti $P$ (2015). Enhanced amino acid utilization sustains growth of cells lacking Snf1/AMPK. Biochim Biophys Acta - Mol Cell Res 1853(7): 1615-1625. doi: 10.1016/j.bbamcr.2015.03.014

145. Jeon S-M (2016). Regulation and function of AMPK in physiology and diseases. Exp Mol Med 48(7): e245. doi: 10.1038/emm.2016.81

146. Grahame Hardie D (2014). AMP-activated protein kinase: a key regulator of energy balance with many roles in human disease. $\mathbf{J}$ Intern Med 276(6): 543-59. doi: 10.1111/joim.12268

147. Faubert B, Boily G, Izreig S, Griss T, Samborska B, Dong Z, Dupuy F, Chambers C, Fuerth BJ, Viollet B, Mamer OA, Avizonis D, DeBerardinis RJ, Siegel PM, and Jones RG (2013). AMPK is a negative regulator of the Warburg effect and suppresses tumor growth in vivo. Cell Metab 17(1): 113-24. doi: 10.1016/j.cmet.2012.12.001

148. Faubert B, Vincent EE, Poffenberger MC, and Jones RG (2015). The AMP-activated protein kinase (AMPK) and cancer: Many faces of a metabolic regulator. Cancer Lett 356(2): 165-170. doi: 10.1016/j.canlet.2014.01.018

149. Jeon S-M, Chandel NS, and Hay N (2012). AMPK regulates NADPH homeostasis to promote tumour cell survival during energy stress. Nature 485(7400): 661-5. doi: 10.1038/nature11066 